Supplement of Magn. Reson., 1, 175-186, 2020

https://doi.org/10.5194/mr-1-175-2020-supplement

(C) Author(s) 2020. This work is distributed under

the Creative Commons Attribution 4.0 License.

(c) (i)

Supplement of

\title{
Geminal parahydrogen-induced polarization: accumulating long-lived singlet order on methylene proton pairs
}

\section{Laurynas Dagys et al.}

Correspondence to: Malcolm H. Levitt (mhl@ soton.ac.uk)

The copyright of individual parts of the supplement might differ from the CC BY 4.0 License. 


\section{S1 Chemical structure determination of I}

The compound sodium 4-(carboxylatomethyl)-5-oxo-2,5-dihydrofuran-2,3-dicarboxylate (I) is created in low concentration in water, on the order of few mmol during the hydrogenation of acetylene dicarboxylic acid disodium salt to form fumaric acid disodium salt using the catalyst $\left[\mathrm{Cp}^{*} \mathrm{Ru}\left(\mathrm{CH}_{3} \mathrm{CN}\right)_{3}\right] \mathrm{PF}_{6}$. The low concentration of $\mathbf{I}$ made its characterization challenging. It turned out to be impossible to isolate a sufficient amount of $\mathbf{I}$ to allow a full characterization. The chemical structure of $\mathbf{I}$ was therefore confirmed by comparing its NMR characteristics with the salt $\mathbf{S - 3}$ synthesized by the route shown in figure S1. As discussed below, the ${ }^{1} \mathrm{H}$ NMR spectra of the hydrogenation product $\mathbf{I}$ and the salt $\mathrm{c}$ are exactly superimposed at all $\mathrm{pH}$ values, with a mixture of the two never displaying any additional peaks. We conclude that $\mathbf{I}$ and $\mathbf{S - 3}$ are identical.
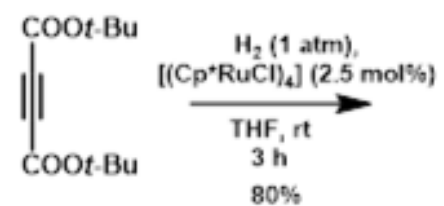

$80 \%$<smiles>CCCCCCCC(C)(C)C</smiles>

S-1

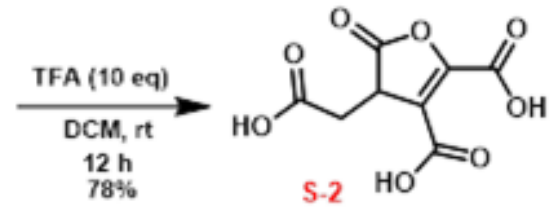

S-2

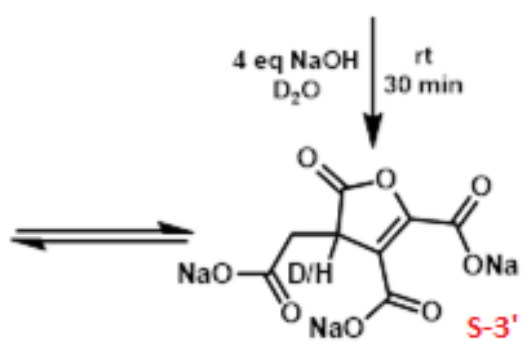

Figure S1. Synthetic route to the salt $\mathbf{S - 3}$, which is shown to be identical to the hydrogenation product $\mathbf{I}$.

\section{S1.1 Synthesis of S-3}

Di-tert-butyl 5-(tert-butoxy)-4-(2-(tert-butoxy)-2-oxoethyl)furan-2,3-dicarboxylate (S-1)

Following a reported procedure Guthertz et al. (2018), hydrogen gas was bubbled through a stirred solution of $\left[\mathrm{Cp}^{*} \mathrm{RuCl}_{4}\right](48$ $\mathrm{mg}, 0.0442 \mathrm{mmol}, 2.5 \mathrm{~mol} \%)$ in THF ( $15 \mathrm{~mL}$ ) for $5 \mathrm{~min}$. Di-tert-butyl acetylenedicarboxylate ( $400 \mathrm{mg}, 1.77 \mathrm{mmol})$ was added and stirring was continued for $3 \mathrm{~h}$ under a $\mathrm{H}_{2}$ atmosphere. For work up, all volatile materials were removed under vacuum and the residue was purified by flash chromatography (hexanes/EtOAc, 4/1) to yield compound $\mathbf{S}-\mathbf{1}$ as pale yellow oil (321 $\mathrm{mg}$, $80 \%) .{ }^{1} \mathrm{H}$ NMR $\left(500 \mathrm{MHz}, \mathrm{CDCl}_{3}\right): \delta 3.32(\mathrm{~s}, 2 \mathrm{H}), 1.54(\mathrm{~s}, 9 \mathrm{H}), 1.53(\mathrm{~s}, 2 \mathrm{H}), 1.41(\mathrm{~s}, 9 \mathrm{H}), 1.40(\mathrm{~s}, 9 \mathrm{H}) .{ }^{13} \mathrm{C}$ NMR $(126$ $\left.\mathrm{MHz}, \mathrm{CDCl}_{3}\right): \delta 169.7,162.0,157.1,155.6,135.2,126.4,100.8,85.6,81.9,81.0,29.7,28.6,28.2,28.1,28.0$. ESI-MS calcd for $\mathrm{C}_{2} 4 \mathrm{H}_{3} 9 \mathrm{O}_{8}(M+H)^{+} 455.2639$; found: 455.2651 .

\section{4-(Carboxymethyl)-5-oxo-4,5-dihydrofuran-2,3-dicarboxylic acid (S-2)}

To a stirred solution of ester $\mathbf{S - 1}(200 \mathrm{mg}, 0.44 \mathrm{mmol})$ in dichloromethane $(8 \mathrm{~mL})$ was added TFA $(337 \mu \mathrm{L}, 4.4 \mathrm{mmol})$ at $0{ }^{\circ} \mathrm{C}$. The mixture was warmed to $\mathrm{rt}$ and stirred for $12 \mathrm{~h}$ at the same temperature. The volatile materials were removed under vacuum and the residue was triturated with $\mathrm{Et}_{2} \mathrm{O}$ to afford acid $\mathbf{S - 2}(79 \mathrm{mg}, 78 \%)$ as a sufficiently pure colorless solid. ${ }^{1} \mathrm{H}$ NMR $\left(400 \mathrm{MHz},\left(\mathrm{CD}_{3}\right)_{2} \mathrm{CO}\right): \delta 5.74(\mathrm{dd}, 1 \mathrm{H}, J=1.4,0.8 \mathrm{~Hz}), 3.83(\mathrm{dd}, 1 \mathrm{H}, J=16.9,1.4 \mathrm{~Hz}), 3.72(\mathrm{dd}, 1 \mathrm{H}, J=16.9,0.8$ $\mathrm{Hz}),{ }^{13} \mathrm{C}$ NMR $\left(126 \mathrm{MHz},\left(\mathrm{CD}_{3}\right)_{2} \mathrm{CO}\right): \delta 172.2,169.7,169.6,160.9,148.3,133.9,79.9,28.0$. ESI-MS calcd for $\mathrm{C}_{2} 4 \mathrm{H}_{3} 9 \mathrm{O}_{8}$ $(M-H)^{-}$228.9990; found: 228.9971 . The acid $\mathbf{S - 2}$ was then converted to the corresponding tetrasodium salt $\mathbf{S - 3}$ by adding 4 eq. of $\mathrm{NaOH}$ and stirring for $30 \mathrm{~min}$ in $\mathrm{D}_{2} \mathrm{O}$. 


\section{S1.2 Structure determination of S-3}

Figures S2 - S6 show the NMR spectra acquired for the determination of the chemical structure of the acid S-2. The molecular structure of the synthesised acid S-2, was determined to be 4-(carboxylatomethyl)-5-oxo-2,5-dihydrofuran- 2,3-dicarboxylate. Therefore its sodium salt $\mathbf{S - 3}$ is sodium 4-(carboxylatomethyl)-5-oxo-2,5-dihydrofuran-2,3-dicarboxylate (see figure S1).
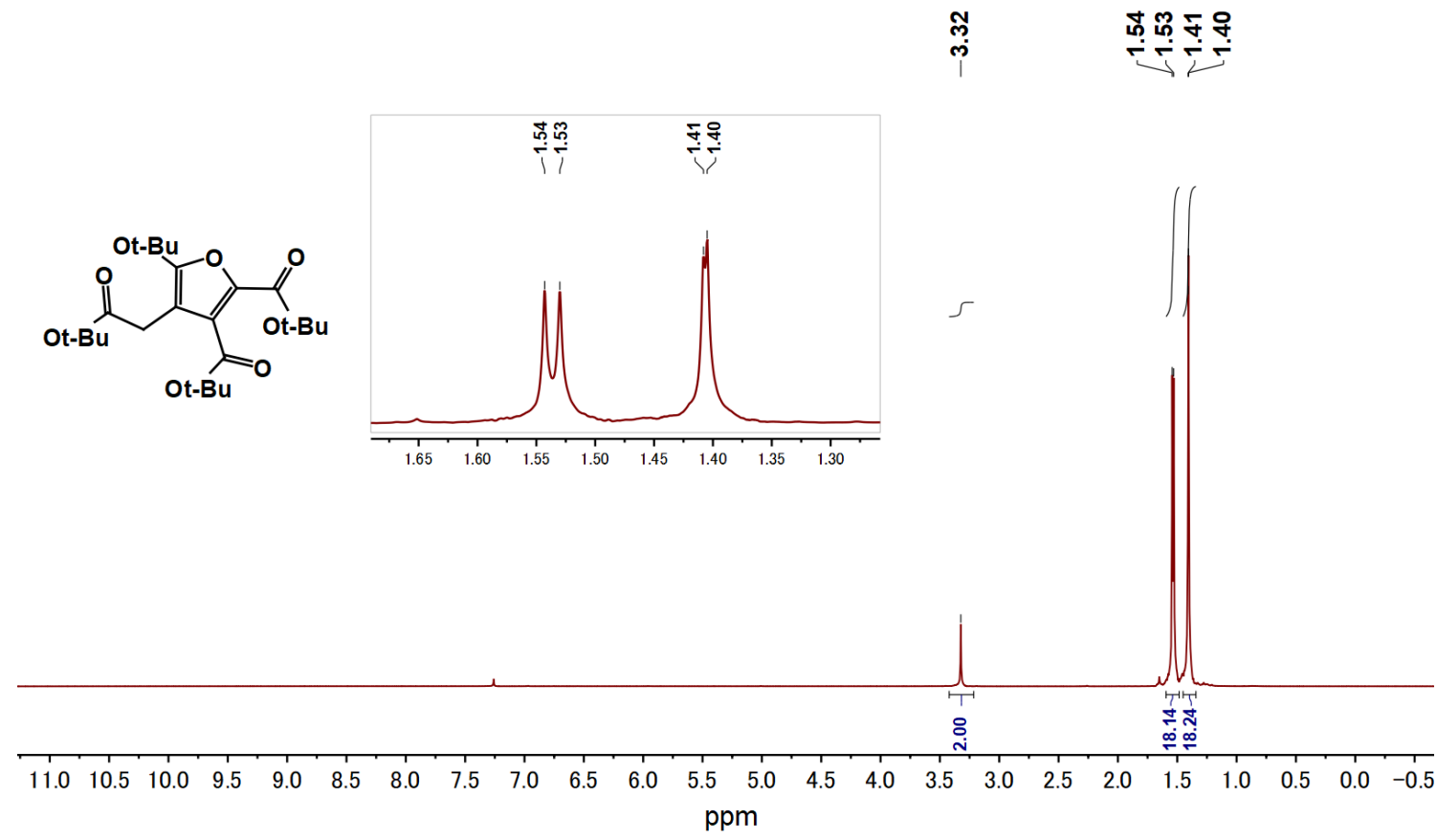

Figure S2. ${ }^{1} \mathrm{H}-\mathrm{NMR}$ spectrum of ester $\mathbf{S - 1}\left(500 \mathrm{MHz}, \mathrm{CDCl}_{3}\right)$ 


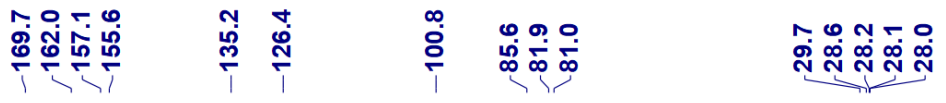
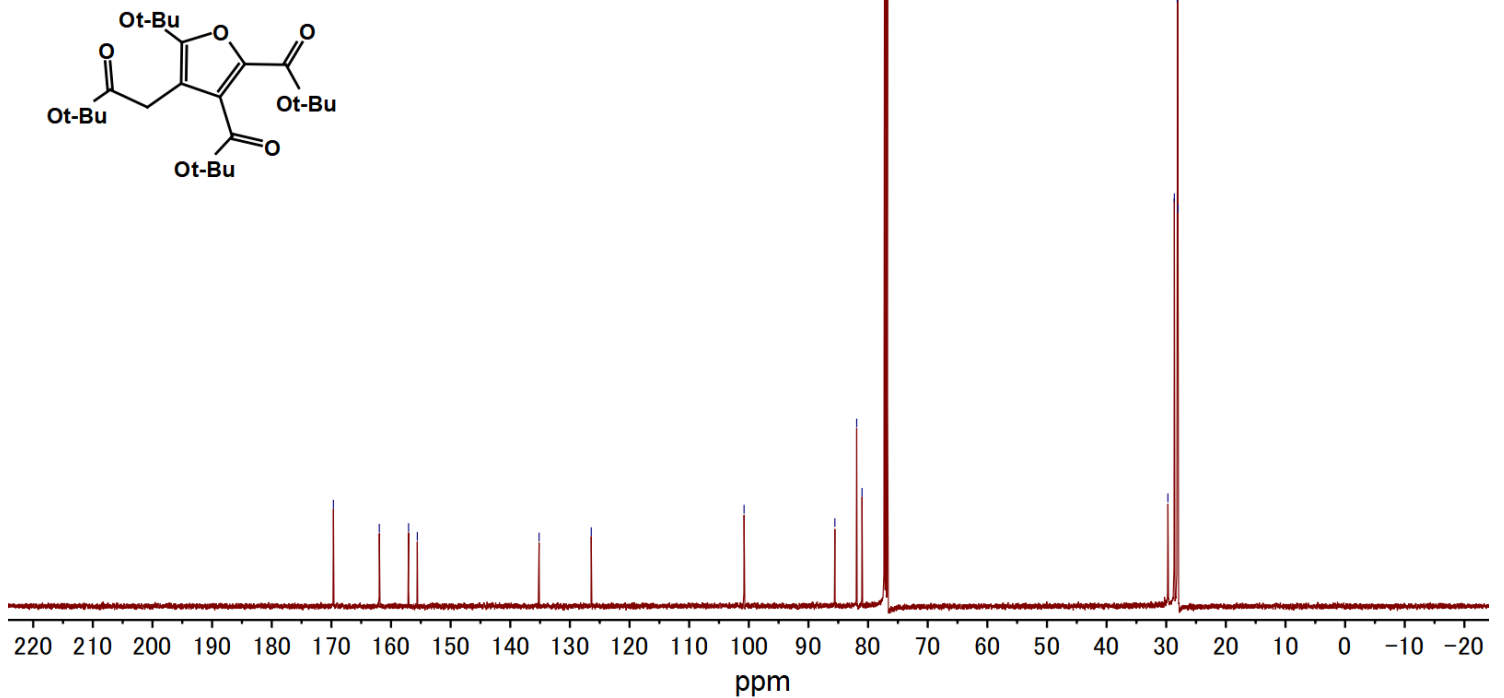

Figure S3. ${ }^{13} \mathrm{C}-\mathrm{NMR}$ spectrum of ester $\mathbf{S - 1}\left(126 \mathrm{MHz}, \mathrm{CDCl}_{3}\right)$

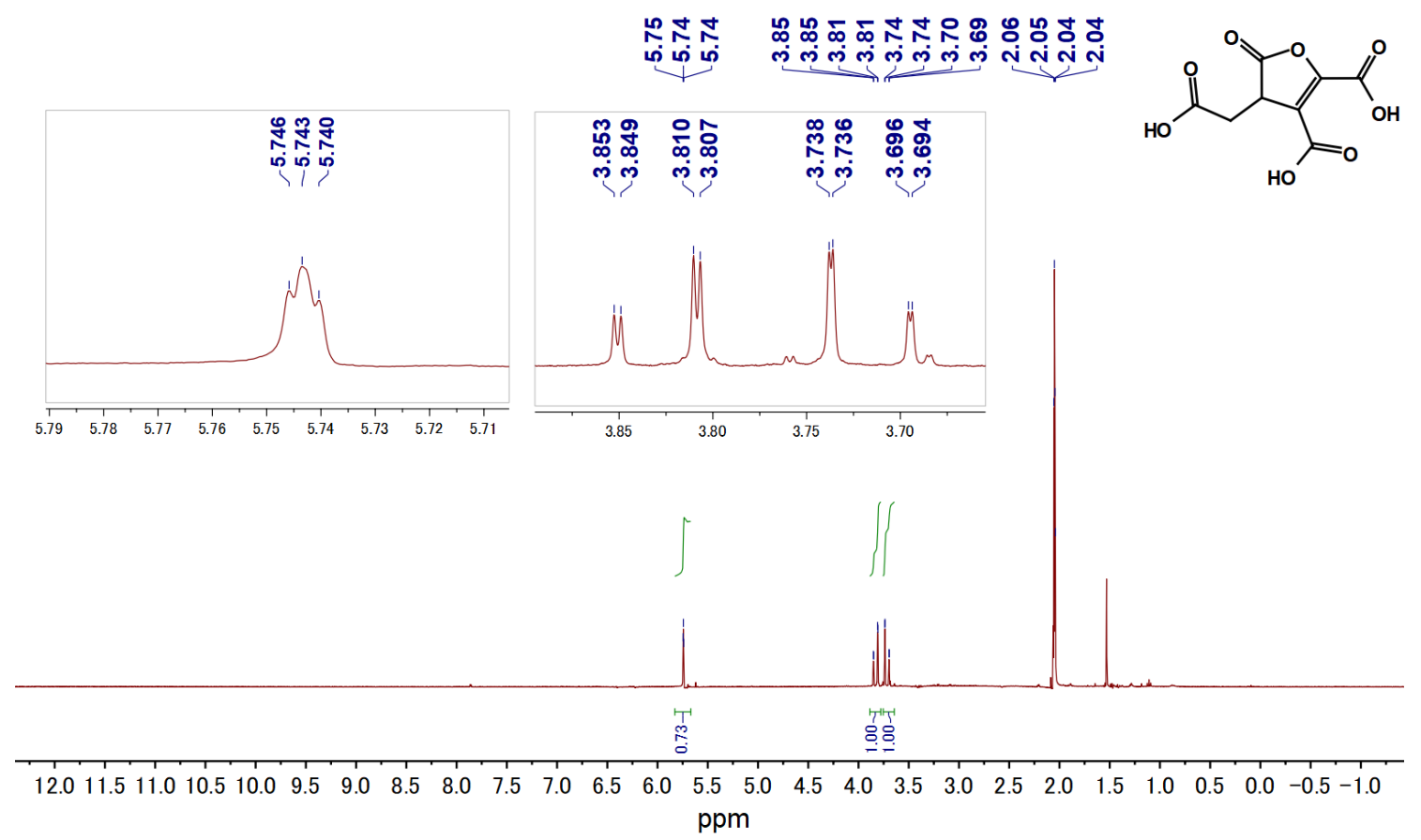

Figure S4. ${ }^{1} \mathrm{H}-\mathrm{NMR}$ spectrum of acid $\left.\mathbf{S - 2}\left(400 \mathrm{MHz},\left(\mathrm{CD}_{3}\right)_{2} \mathrm{CO}\right)\right)$ 


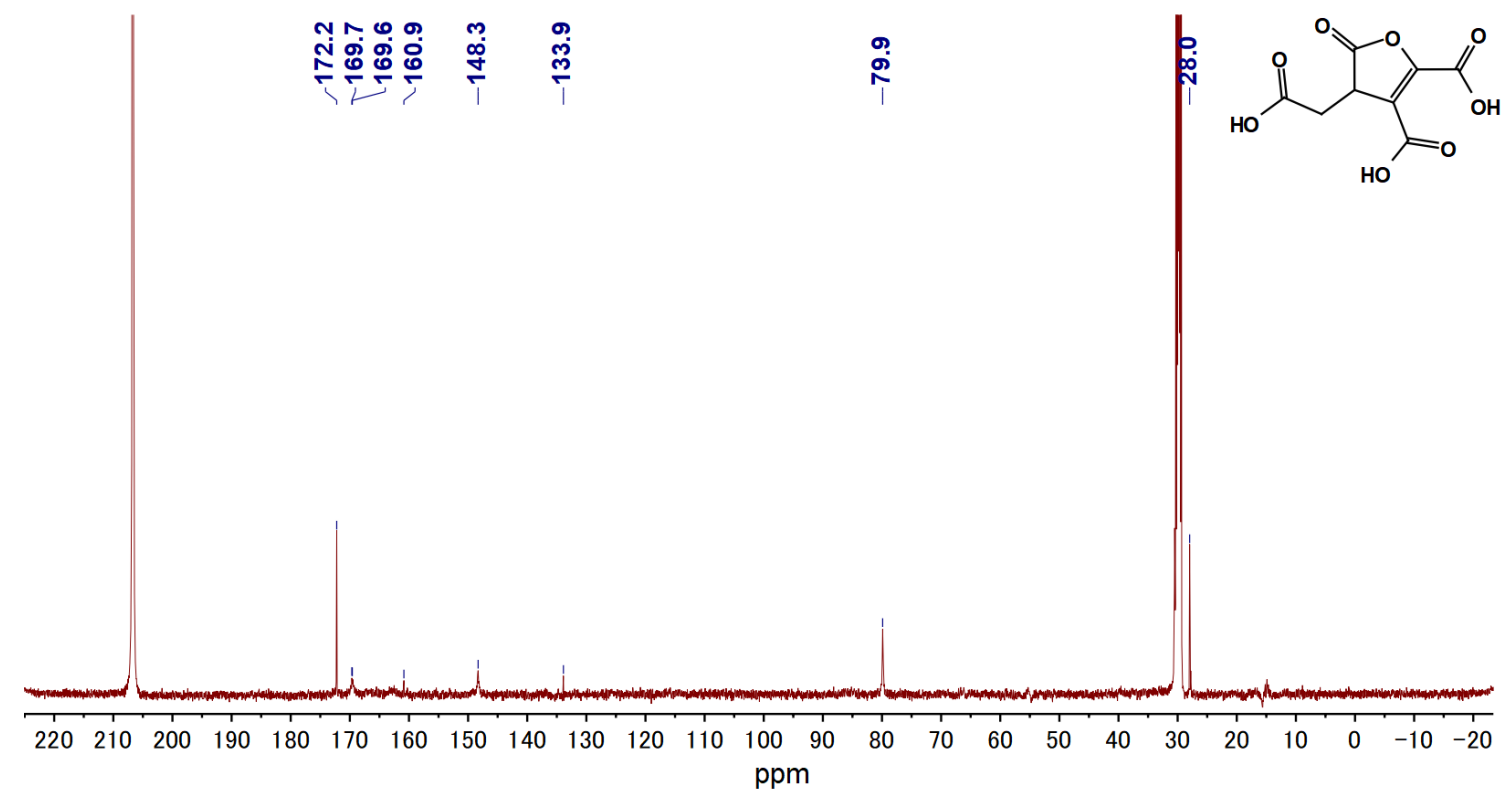

Figure S5. ${ }^{13} \mathrm{C}-\mathrm{NMR}$ spectrum of acid $\left.\mathbf{S - 2}\left(126 \mathrm{MHz},\left(\mathrm{CD}_{3}\right)_{2} \mathrm{CO}\right)\right)$

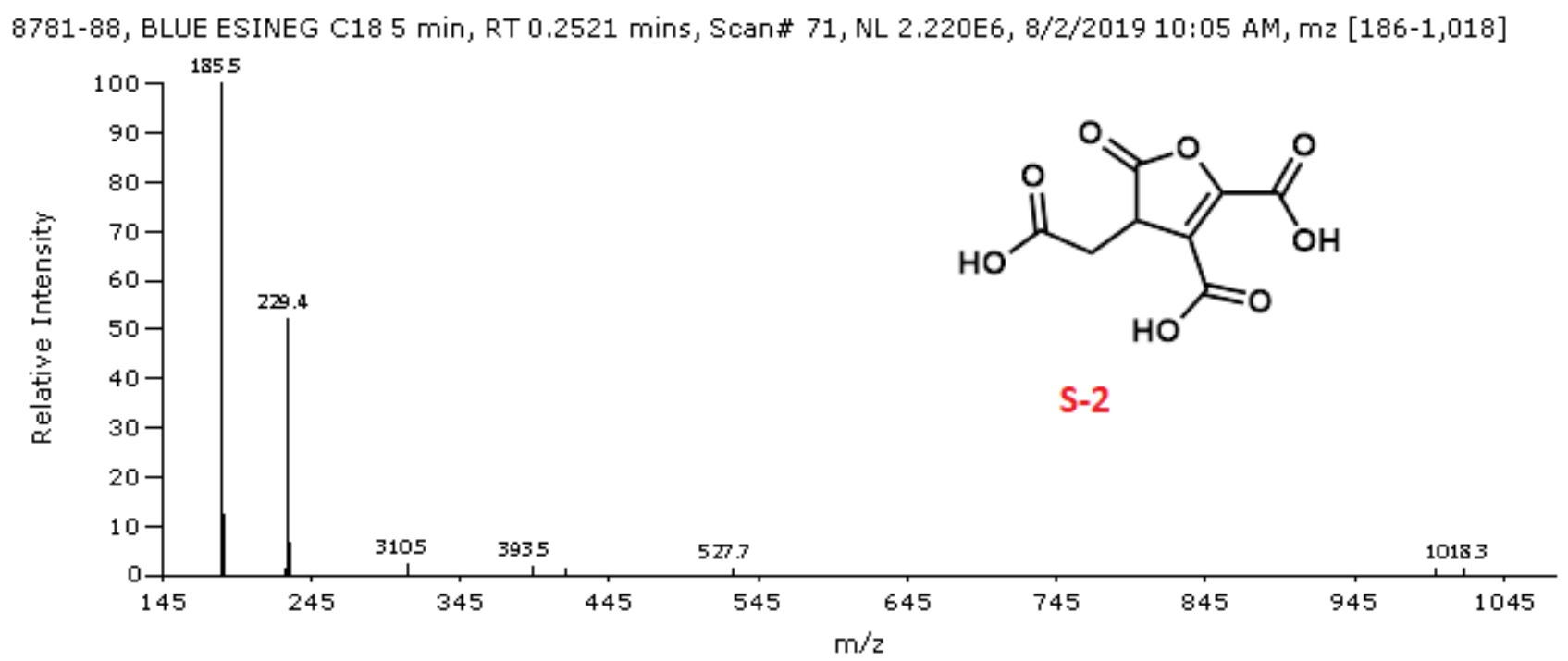

Figure S6. Mass spectrometry of acid S-2

\section{S1.3 Identity of S-3 and I}

Figure S7 shows proton NMR spectra of the pure synthesised compound S-3 and of a mixture of synthesised S-3 with the reaction product solution containing the molecule $\mathbf{I}$. Since the NMR characteristics of $\mathbf{S - 3}$ and $\mathbf{I}$ are indistinguishable, it was concluded that the molecules $\mathbf{I}$ and $\mathbf{S - 3}$ are identical. 


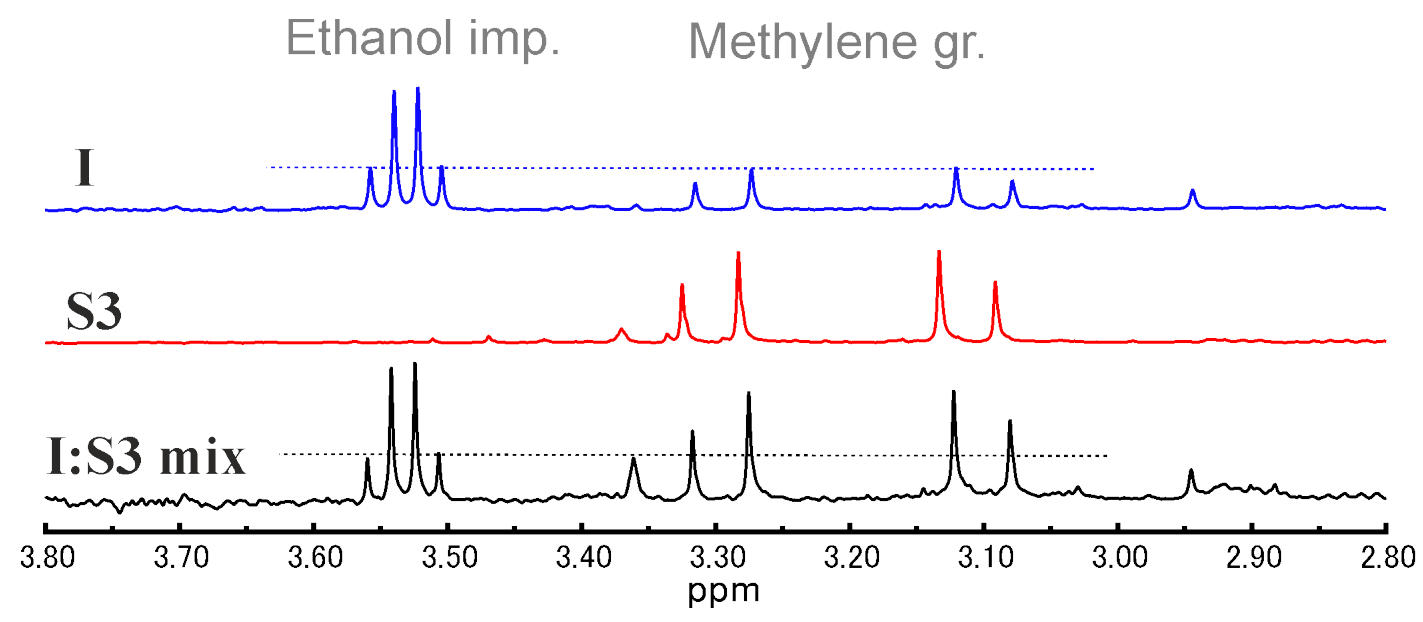

Figure S7. ${ }^{1} \mathrm{H}$ NMR spectra of the gemPHIP product I (blue), the synthesised salt S-3 (red) and the I:S-3 mixture (black), all dissolved into $\mathrm{D}_{2} \mathrm{O} / \mathrm{H}_{2} \mathrm{O}$ solution. Guiding lines are given with respect to the ethanol impurity observed in the first and the last spectra. The addition of synthesised molecule only increases the signal of the methylene group protons which supports that $\mathbf{I}$ has the same identity as $\mathbf{S - 3}$.

\section{S2 Singlet decay time constant of the geminal protons}

Samples for $T_{\mathrm{S}}$ measurements with thermal polarization were prepared as follows: A hydrogenation reaction was performed by bubbling hydrogen at 6 bar pressure for 5 minutes through the sample solution at an elevated temperature of $60^{\circ} \mathrm{C}$ to obtain a detectable amount of $\mathbf{I}$. Prepared samples were degassed by 5 min nitrogen bubbling at atmospheric pressure and vacuumsealed to reduce the amount of paramagnetic oxygen. The reference sample contained $30 \mathrm{mM}$ of synthesized substance $\mathbf{I}$ in $\mathrm{D}_{2} \mathrm{O}$ and was degassed identically. For experiments on thermal equilibrium samples, a recycle delay of $10 \mathrm{~s}$ was used between NMR experiments. The experiments were performed at a temperature of $22^{\circ} \mathrm{C}$.

The time constant for singlet order decay was estimated by conventional NMR on a degassed sample at room temperature $\left(22^{\circ} \mathrm{C}\right)$. To measure $T_{\mathrm{S}}$ the singlet spin order was populated using the Sarkar pulse sequence (Sarkar et al. (2007); Levitt (2012)), followed by the application of a spin-locking field was for a variable duration. Afterwards, the remaining singlet spinorder was converted back into observable magnetization and the NMR signal acquired (see figure S8). A sufficiently strong proton decoupling field is necessary to suppress the magnetic inequivalence of the two protons (Pileio and Levitt (2009)). 




Figure S8. Pulse sequence used for determination of singlet state lifetime $T_{S}$ on thermally polarized samples. The singlet spin order was populated using the Sarkar pulse sequence, then a spin-locking field was applied for a variable duration, followed by reconversion of the singlet spin order into observable magnetization and acquisition of the NMR signal. A phase cycle given by $\phi_{1}=[\mathrm{x}, \mathrm{y},-\mathrm{x},-\mathrm{y}], \phi_{2}=[\mathrm{y},-\mathrm{x}$, $-\mathrm{y}, \mathrm{x}], \phi_{3}=[\mathrm{y}, \mathrm{y}, \mathrm{y}, \mathrm{y}]$ and $\phi_{4}=[\mathrm{x}, \mathrm{x}, \mathrm{x}, \mathrm{x}]$ is used to filter out unwanted signal components created by the initial Sarkar sequence. The timings are given by: $\tau_{4}=1 / 4 J$ and $\tau_{3}=\pi / \omega_{\Delta}$, where $\omega_{\Delta}$ is chemical shift different between two nuclear spins.

We have determined $T_{\mathrm{S}}=61.1 \pm 7.1 \mathrm{~s}$ and $T_{1}=1.23 \pm 0.14 \mathrm{~s}$ at $9.41 \mathrm{~T}$ for a reaction product solution containing in average between 60 and $70 \mathrm{mM}$ precursor disodium acetylenedicarboxylate, between 20 and 30 mM reaction product disodium fumarate, up to $10 \mathrm{mM}$ catalytic side product $\mathbf{I}$ and $6 \mathrm{mM}$ catalyst $\left[\mathrm{Cp}^{*} \mathrm{Ru}\left(\mathrm{CH}_{3} \mathrm{CN}\right)_{3}\right] \mathrm{PF}_{6}$ in $\mathrm{D}_{2} \mathrm{O}$. Results are shown in figure S9. For comparison, the measurements were repeated on a degassed solution containing only $30 \mathrm{mM}$ of the chemically synthesized version of $\mathbf{I}$ in $\mathrm{D}_{2} \mathrm{O}$. The results were found to agree within experimental error. We have, thus, negated potentially problematic factors, such as relaxation due to the presence of a catalyst.


Figure S9. Determination of $T_{1}$ (a.) and $T_{\mathrm{S}}$ (b.) using inversion recovery and pulse sequence from figure S8, respectively. Experiments were carried-out in $9.41 \mathrm{~T}$ magnetic field at $22^{\circ} \mathrm{C}$. The estimated values are given in the plots. Note the difference between the timescales of the experiments.

In order to determine which spin-locking amplitude is sufficient to reach the near equivalence regime, where the influence of the chemical shift difference between the protons is suppressed, the singlet decay experiment was carried out with different 
spin-locking powers and at different magnetic fields. The singlet state relaxation rate $R_{\mathrm{S}}\left(=1 / T_{\mathrm{S}}\right)$ is expected to converge asymptotically towards a minimum value where the decoupling is strong enough to be used for singlet state lifetime determination. Figure $\mathrm{S} 10$ shows the convergence of $T_{\mathrm{S}}^{-1}$ to a minimum value for large spin-locking nutation frequencies, corresponding to maximum $T_{\mathrm{S}}$ times of $39 \mathrm{~s}$ at $16.4 \mathrm{~T}$ and $61 \mathrm{~s}$ at $9.41 \mathrm{~T}$. The results indicate that a spin-locking nutation frequency of $1 \mathrm{kHz}$ is sufficient to reach the near-equivalence regime at $9.41 \mathrm{~T}$. The $T_{1}$ of the protons was measured by inversion recovery experiments on the same sample at $9.41 \mathrm{~T}$, and found to be $T_{1}=1.23 \pm 0.14 \mathrm{~s}$, a factor of 50 shorter than $T_{\mathrm{S}}$.

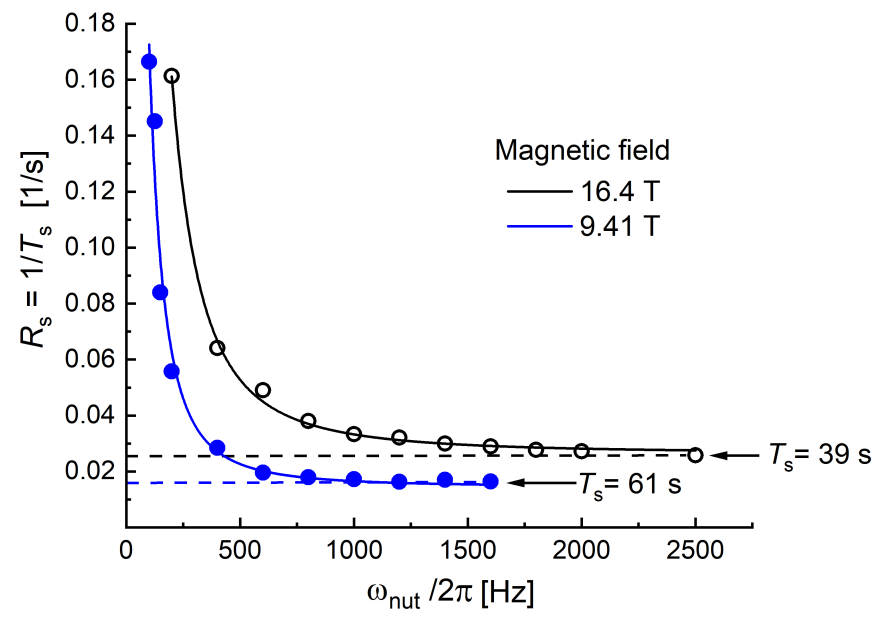

Figure S10. Singlet order relaxation rate constant $R_{\mathrm{S}}=1 / T_{\mathrm{S}}$ plotted against spin-locking nutation frequencies $\nu_{n u t}=\omega_{\text {nut }} / 2 \pi$ in Hz. The value of $T_{\mathrm{S}}^{-1}$ converges to a field-dependent minimum value, corresponding to maximum $T_{\mathrm{S}}$ times of $39 \mathrm{~s}$ at $16.4 \mathrm{~T}$ and $61 \mathrm{~s}$ at $9.41 \mathrm{~T}$. The near equivalence regime is reached for spin-locking nutation frequencies from $1 \mathrm{kHz}$ upwards. The measurements were carried out on thermally polarized and degassed samples at room temperature $\left(22^{\circ} \mathrm{C}\right)$.

\section{S3 Decomposition of product I}

At sufficiently high temperature, molecule I decomposes into a simpler form with one carboxylic group missing, as depicted in figure S11. The decarboxylation process takes around 2 hours at $333 \mathrm{~K}$ but is accelerated at higher temperatures. Since the chemical structure of II is achiral, its methylene protons are chemically equivalent, in contrast to those of the chiral compound I. A ${ }^{1} \mathrm{H}$ NMR spectrum showing peaks from the methylene protons of both species is shown in the appendix of the manuscript.

I



II

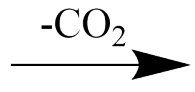

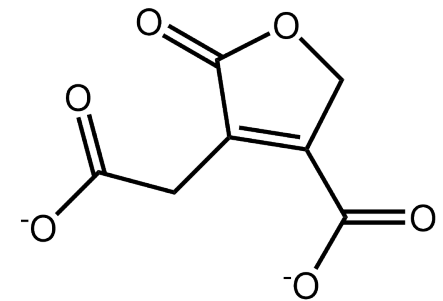

Figure S11. Decarboxylation of the chiral product molecule I into the achiral compound II. 


\section{References}

Guthertz, A., Leutzsch, M., Wolf, L. M., Gupta, P., Rummelt, S. M., Goddard, R., Farès, C., Thiel, W., and Fürstner, A.: Half-Sandwich Ruthenium Carbene Complexes Link Trans-Hydrogenation and Gem-Hydrogenation of Internal Alkynes, J. Am. Chem. Soc., 140, 31563169, 2018.

Levitt, M. H.: Singlet Nuclear Magnetic Resonance, Annu. Rev. Phys. Chem., 63, 89-105, 2012.

Pileio, G. and Levitt, M. H.: Theory of Long-Lived Nuclear Spin States in Solution Nuclear Magnetic Resonance. II. Singlet Spin Locking, J. Chem. Phys., 130, 214 501-14, 2009.

Sarkar, R., Vasos, P. R., and Bodenhausen, G.: Singlet-State Exchange NMR Spectroscopy for the Study of Very Slow Dynamic Processes, J. Am. Chem. Soc., 129, 328-334, 2007. 